\title{
Drug Utilization Evaluation of Anticancer Drugs in a Tertiary Care Teaching Hospital: a Descriptive Observational Study
}

\author{
Vinodkumar Mugada ${ }^{*}$, Aswinichand Paruchuri, Mounika Munagala \\ Department of Pharmacy Practice Aditya Pharmacy College Surampalem, Kakinada, India.
}

\begin{tabular}{|c|c|}
\hline ARTICLE INFO & ABSTRACT \\
\hline Article history: & \multirow{7}{*}{$\begin{array}{l}\text { Drug Utilization Evaluation (DUE) promotes rational use of drugs. The aim of present study was to conduct } \\
\text { DUE of anticancer drugs. Newly diagnosed and/or known case of carcinoma which required treatment with } \\
\text { chemotherapy, patients of both sex, and age }>18 \text { years were included in the study. Patients diagnosed as having } \\
\text { carcinoma that also required surgical intervention, radiotherapy or other modality of management were excluded } \\
\text { from the study. WHO core prescribing indicators are used to know about polypharmacy, excessive use of } \\
\text { antibiotics, percentage of drugs prescribed by from Essential Drugs List (EDL). Females were commonly } \\
\text { affected than males. Patients of age group } 41-50 \text { years (mean } 52.43 \text {, SD } \pm 7.77 \text { ) constituted the highest number, } \\
34 \% \text { and } 13 \% \text { in rural and urban population respectively. 5-Flurouracil and Cisplatin are most commonly } \\
\text { prescribed anticancer drugs followed by Cyclophosphamide. The most commonly used adjuvant drugs in our } \\
\text { study are Diclofenac, B-Complex, Granisetron, Ranitidine, Dexamethasone, Ondansetron, and Mannitol. The } \\
\text { cytoprotectant drugs observed in our study are Leucovorin, Mesna and Peg-Filgrastim. Average number of } \\
\text { Cytotoxic Drugs per prescription was } 1.97 \text {. Average number of drugs per prescription was } 8.16 \text {. Percentage of } \\
\text { drugs prescribed from Essential Drugs List (EDL) was } 88.4 \% \text {. Percentage of encounters with an antibiotic } \\
\text { prescribed was } 54.8 \% \text {. Polypharmacy, unnecessary antibiotic and injection prescribing were not observed. The } \\
\text { percentage of drugs from EDL may be improved. }\end{array}$} \\
\hline Received on: 11/06/2016 & \\
\hline Revised on: 14/07/2016 & \\
\hline Accepted on: $23 / 08 / 2016$ & \\
\hline Available online: $29 / 10 / 2016$ & \\
\hline Key words: & \\
\hline $\begin{array}{l}\text { Drug Utlization Evaluation, } \\
\text { Essential Drugs List, WHO } \\
\text { core prescribing indicators, } \\
\text { polypharmacy, rational. }\end{array}$ & \\
\hline
\end{tabular}

\section{INTRODUCTION}

Cancer is one of the common cause of deaths in India and has profound social and economic consequences, often leading to family impoverishment and societal inequity (Mohandas et al., 2014). According to the WHO, annually people die of cancer in India with prevalence of 500,000, this number is expected to rise to 700,000 by 2015 (IANS, 2014). The global burden of cancer continues to increase largely because of the aging and growth of the world population alongside an increasing adoption of cancer-causing behaviours (Jemal et al., 2011; Takiar et al., 2010), particularly smoking, in economically developing

\footnotetext{
* Corresponding Author Vinodkumar Mugada, Department of Pharmacy Practice Aditya Pharmacy College Surampalem, Kakinada, India. Email: mugadavinodkumar18 @ gmail.com
}

countries. Drug utilization evaluation (DUE) is system of ongoing, systemic, criteria-based evaluation of drug use that will help ensure that medicines are used appropriately at the individual patient level. Drug utilization is drug or disease specific and can be structured so that it will assess the actual process of prescribing, dispensing or administering a drug (WHO, 2003). Potent cytotoxic drugs like anticancer drugs acts on both cancerous cells and healthy living cells. It makes the healthy living cells vulnerable to the cytotoxic action of anticancer drugs. In this context, DUE of these anticancer drugs was imperative. Irrational use of drugs is a major health problem of present day medical practice. This in turn leads to different consequences including but not limited to ineffective treatment, unnecessary prescription of drugs particularly antimicrobials and injections, development of resistance to antibiotics, adverse effects and economic burden on both patients and society. 
Irrational prescriptions and use of drugs has for long been known to be a feature of health care settings of developing countries, and is characterized by poly pharmacy, excessive use of antibiotics and injections and use of drugs of doubtful efficacy (Igbiks and Joseph, 2012). World Health Organization developed a core prescribing indicators to measure the degree of polypharmacy, the tendency to prescribe drugs by generic name and the overall level of use of antibiotics and injections. The degree to which the prescribing practice conformed to the essential drug list, formulary or standard treatment guideline were also measured by searching for the number of drugs prescribed from essential drug list available (WHO, 1993). Prescribers can only treat patients in a rational way if they have access to an essential drugs list and essential drugs are available on a regular basis (Sunil et al., 2005).

\section{METHODOLOGY}

This descriptive study was carried out in chemotherapy ward, government general hospital; Kakinada for duration of 6 months. Total of 150 prescriptions had been reviewed. Newly diagnosed and/or known case of carcinoma which required treatment with chemotherapy, patients of both sex, and age $>18$ years were included in the study. Patients diagnosed as having carcinoma that also required surgical intervention, radiotherapy or other modality of management were excluded from the study. The data required for present study was noted down from the case sheets of the patients in a data collection form. WHO core prescribing indicators was compiled at the end of the study to know the amount of prescriptions with polypharmacy, percentage of prescriptions with injectables and antibiotics, percentage of drugs prescribed from Essential Drugs list etc. The study was approved by Institutional Ethical Committee. Informed consent was waived since there is no interaction with patients.

\section{RESULTS AND DISCUSSION}

Patients of age group 41-50 years (mean 52.43, SD \pm 7.77) constituted the highest number, $34 \%$ and $13 \%$ in rural and urban population respectively. Similar findings were reported in some studies (Sneha et al., 2015; Mary Rohini et al., 2015; Damodar et al., 2011). The accumulation of age-associated changes in a biochemical process that helps control genes may be responsible for some of the increased risk of cancer seen in older people, according to a National Institutes of Health study. Scientists have known for years that age is a leading risk factor for the development of many types of cancer, but why aging increases cancer risk remains unclear.

Researchers suspect that DNA methylation, or the binding of chemical tags, called methyl groups, onto DNA, may be involved. Methyl groups activate or silence genes, by affecting interactions between DNA and the cell's protein-making machinery. According to the 1994 Surveillance, Epidemiology, and End Results Program of the National Cancer Institute, over $50 \%$ of all cancers occur in patients who are older than 65 years of age. Females were more commonly affected than males. Similar findings were reported in some studies (Kirthi et al., 2014; Kulkarni et al., 2014; Popoola et al., 2013). Males were more commonly affected by cancer when compared to females in some studies (Rathi et al., 2007; Goyal et al., 2014). Gender differences in susceptibility to a disease are a very useful piece of information that can be used to develop a causal hypothesis for the disease, or to define subgroups at highest risk for preventive action. The gender differential in susceptibility can give important clues for the etiology of cancers.

Table 1: Age wise distribution

\begin{tabular}{cccc}
\hline S.No. & Age (in years) & Rural & Urban \\
\hline 1 & $21-30$ & 0 & 6 \\
2 & $31-40$ & 9 & 5 \\
3 & $41-50$ & 34 & 13 \\
4 & $51-60$ & 26 & 18 \\
5 & $61-70$ & 16 & 17 \\
6 & $71-80$ & 2 & 2 \\
7 & $81-90$ & 0 & 2 \\
\hline
\end{tabular}

Table 2: Gender wise distribution.

\begin{tabular}{cccc}
\hline S.No. & Gender & Rural & Urban \\
\hline 1 & Male & 27 & 31 \\
2 & Female & 64 & 28 \\
\hline
\end{tabular}

Table 3: Prescribing pattern of anticancer drugs.

\begin{tabular}{clccc}
\hline S.No. & \multicolumn{1}{c}{ Drugs } & Male & Female & Total \\
\hline 1 & Inj. 5-FU & 31 & 49 & 80 \\
2 & Inj. Cisplatin & 39 & 21 & 60 \\
3 & Inj. Oxaliplatin & 5 & 1 & 6 \\
4 & Inj. Carboplatin & 2 & 8 & 10 \\
5 & Inj. Epirubicin & 1 & 0 & 1 \\
6 & Inj. Acitnomycin D & 1 & 11 & 12 \\
7 & Inj. Doxorubicin & 3 & 33 & 36 \\
8 & Inj. Paclitaxel & 11 & 19 & 30 \\
9 & Inj. Cyclophosphamide & 1 & 38 & 39 \\
10 & Inj. Etoposide & 4 & 1 & 5 \\
11 & Inj. Ifosfamide & 0 & 4 & 4 \\
12 & Inj. Dacarbazine & 2 & 0 & 2 \\
13 & Inj. Vinblastine & 1 & 0 & 1 \\
14 & Inj. Vincristine & 1 & 0 & 1 \\
15 & Inj. Mytomycin C & 0 & 9 & 9 \\
\hline
\end{tabular}

5-Flurouracil and Cisplatin are most commonly prescribed anticancer drugs followed by cyclophosphamide. Similar findings were observed in some studies (Mary Rohini et al., 2015; Goyal et al., 2014; Darshan et al., 2014).

The effective prescribing of anticancer drugs is based upon the availability of drugs, cost, tolerance, efficacy, progression of cancer in patient. Recently, many effective anticancer drugs were explored in which the detailed side effect profile and efficacy was not reported. In that context, it is better to use already established drugs which are effective and for which the side effect profile was well known. Of the 21 anticancer drugs listed in hospital formulary, only 15 anticancer drugs were prescribed during study period. 
Table 4: List of Cytoprotectant drugs.

\begin{tabular}{clccc}
\hline S. No. & Drugs & Male & Female & Total \\
\hline 1 & Inj. Peg Filgrastim & 0 & 1 & 1 \\
2 & Inj. Leucovorin & 6 & 3 & 9 \\
3 & Inj. Mesna & 0 & 2 & 2 \\
\hline
\end{tabular}

The cytoprotectant drugs observed in our study are Leucovorin, Mesna and Peg- Filgrastim. Leucovorin is a biochemical modulating agent, chemo protective agent used in combination with 5-FU for treatment of advanced head and neck cancer, esophageal cancer. Filgrastim is a human recombinant granulocyte colony stimulating factor which is used to prevent chemotherapy-induced neutropenia, to increase neutrophil counts, and to prevent infection. Mesna conjugates with acrolein, a nephrotoxic metabolite produced by drugs like Cyclophosphamide, Ifosfamide etc, in urine reducing the incidence of renal toxicity.

Dexrazoxane is not recommended for routine use in breast cancer (BC) in adjuvant setting, or metastatic setting with initial doxorubicin-based chemotherapy. Consider use with metastatic BC and other malignancies, for patients who have received more than $300 \mathrm{mg} / \mathrm{m}^{2}$ doxorubicin who may benefit from continued doxorubicin-containing therapy. Cardiac monitoring should continue in patients receiving doxorubicin. Amifostine may be considered for prevention of cisplatin-associated nephrotoxicity, reduction of grade 3 to 4 neutropenia (alternative strategies are reasonable), and to decrease acute and late xerostomia with fractionated radiation therapy alone for head and neck cancer. It is not recommended for protection against thrombocytopenia, prevention of platinum-associated neurotoxicity or ototoxicity or paclitaxel-associated neuropathy, prevention of radiation therapy-associated mucositis in head and neck cancer, or prevention of esophagitis during concurrent chemoradiotherapy for non-small-cell lung cancer (Martee et al., 2009).

Table 5: List of adjuvant drugs.

\begin{tabular}{llccc}
\hline S.No. & Drugs & Males & Females & Total \\
\hline 1 & Tab. Diclofenac & 67 & 83 & 150 \\
2 & Tab. B complex & 67 & 83 & 150 \\
3 & Inj. Tramadol & 1 & 0 & 1 \\
4 & Inj. Mannitol & 39 & 24 & 63 \\
5 & Inj. Mag. Sulphate & 37 & 25 & 62 \\
6 & Inj. Granisetron & 67 & 83 & 150 \\
7 & Inj. Rantidine & 67 & 83 & 150 \\
8 & Inj. Dexamethasone & 67 & 83 & 150 \\
9 & Inj. Ondansetron & 4 & 49 & 53 \\
\hline
\end{tabular}

The most commonly used adjuvant drugs in our study are Diclofenac, B-Complex, Granisetron, Ranitidine, Dexamethasone, Ondansetron and Mannitol. Similar findings were observed in studies (Mary Rohini et al., 2015; Darshan et al., 2014). Mannitol is given along with Furosemide as a palliative therapy (Darshan et al., 2014).With the correct use of antiemetics, Chemotherapy Induced Nausea and Vomiting can be prevented in almost $70 \%$ to up to $80 \%$ of patients (Jordan et al., 2007). Although not approved as an antiemetic, dexamethasone plays a major role in the prevention of acute and delayed CINV and is an integral component of almost all antiemetic regimens (Jordan et al., 2007; Grunberg, 2007).

Table 6: WHO Core Drug Prescribing Indicators.

\begin{tabular}{lll}
\hline S & WHO Core Drug Prescribing Indicators & Result \\
\hline 1 & Avg. No. of Cytotoxic drugs per Prescription & 1.97 \\
2 & Avg. No. of drugs per Prescription & 8.16 \\
3 & Percentage of encounters with an antibiotic prescribed & $54.8 \%$ \\
4 & Percentage of Encounters with an Cytotoxic Injectable & $100 \%$ \\
& prescribed & \\
5 & Percentage of Encounters with an Injectable Prescribed & $75.5 \%$ \\
6 & Percentage of drugs Prescribed from EDL & $88.40 \%$ \\
7 & Percentage of drugs Prescribed from WHO Model List & $80.70 \%$ \\
8 & Percentage of drugs prescribed by generic name & $93 \%$ \\
\hline
\end{tabular}

The average number of drugs per prescription was 8.16. Although it may look like polypharmacy, it must be remembered that definition for polypharmacy differs with clinical setting. Adjuvant drugs like anti-emetics corticosteroids etc makes up the prescription volume. Percentage of prescriptions with an antibiotic prescribed was $54.8 \%$. The antibiotic use was limited to any infections caused by the side effects of drugs like blistering of skin, fungal infections etc. Unnecessary antibiotic prescribing was not observed. Percentage of drugs prescribed from EDL was $88.4 \%$.

The drugs are prescribed based on the hospital formulary and are supplied on nonprofit basis by the government. Incontestably, there might be difference in percentage of drugs prescribed from EDL. The percentage of drugs prescribed from list of essential drugs may be improved .Percentage of drugs prescribed by generic name was $93 \%$. Prescribing medicines by generic name has to be encouraged since generic medicines are as effective as brand ones and they cost less which decreases the medical expenditure.

\section{CONCLUSION}

5-Flurouracil and Cisplatin are most commonly prescribed anticancer drugs followed by cyclophosphamide. The cytoprotectant drugs observed in our study are Leucovorin, Mesna and Peg- Filgrastim. The most commonly used adjuvant drugs in our study are Diclofenac, B-Complex, Granisetron, Ranitidine, Dexamethasone, Ondansetron and Mannitol. The antibiotic use was limited to any infections caused by the side effects of drugs like blistering of skin, fungal infections etc. Unnecessary antibiotic prescribing was not observed. The percentage of drugs prescribed from list of essential drugs may be improved. Polypharmacy was not observed.

\section{ACKNOWLEDGEMENT}

We express our sincere gratitude to Dr. P. Prasanth for his valuable timely suggestions and keen interest that enable us to complete the study. 
Financial support and sponsorship: Nil.

Conflict of Interests: There are no conflicts of interest.

\section{REFERENCES}

2014.

Cancer Incidence to rise five-fold in India by 2025 ? IANS,

Damodar G, Smitha T, Yedukondala Rao A. A descriptive epidemiological study of cancers at a south Indian tertiary care hospital. Research Journal of Pharmaceutical, Biological and Chemical Sciences, 2011; 2 (4): 907-915.

Darshan J Dave, Ajita Pillai, Dimple V Shah, Sneha Agrawal and Anilkumar Goel. An analysis of Utilization Pattern of Anticancer drugs in diagnosed cases of Carcinoma in a tertiary care teaching hospital.International Journal of Basic and Applied Medical Sciences, 2014; 4 (1): 251-259.

Grunberg SM. Antiemetic activity of corticosteroids in patients receiving cancer chemotherapy: Dosing, efficacy, and tolerability analysis. Ann Oncol, 2007; 18:233-240.

How to investigate drug use in health facilities: selected drug use indicators. WHO, 1993: 1-92.

Igbiks T, Joseph O. Drug prescription pattern in a Nigerian tertiary hospital. TJPR, 2012; 11: 146-152.

Jemal A, Bray F, Center MM, Ferlay J, Ward E, Forman D. Global cancer statistics. Cancer J Clin, 2011; 61: 69-90.

Jordan K, Schmoll HJ, Aapro MS. Comparative activity of antiemetic drugs. Crit Rev Oncol Hematol, 2007; 61: 162-175.

Karin Jordan, Christoph Sippel and Hans-Joachim Schmoll. Guidelines for antiemetic treatment of chemotherapy induced nausea and vomiting: past,present and future recommendations. The Oncologist, 2007; 12 (9): 1143-1150.

Kathleen Holloway, Terry Green. Drug and therapeutics committees - A practical guide. WHO, 2003.

Kirthi C, Azra Afza, Mounika Reddy, Syed Aamir Ali, Aparna Yerramilli, Sanjeev Sharma. A study on the adverse effects of anticancer drugs in an oncology center of a tertiary care hospital. International Journal of Pharmacy and Pharmaceutical Sciences, 2014; 6 (2): 580-583.

Kulkarni MD, Samra A Hussaini, Padwa SL, Khandelwa PN, Doifode SM, More PP. Drug utilization review of anticancer drugs in cancer outpatient department of the government medical college, Aurangabad. International Journal of Basic and Clinical Pharmacology, 2014; 3 (5): 879-883.

Martee L Hensley, Karen L Hagerty, Tarun Kewalramani, Daniel M Green, Neal J Meropol, Todd H Wasserman et al. American
Society of Clinical Oncology 2008 Clinical Practice Guideline Update: Use of chemotherapy and radiation therapy protectants. Journal of Clinical Oncology, 2009; 27 (1): 127-145.

Mary Rohini Pentareddy, Suresh AVS, Shailendra D, Subbaratnam Y, Prasuna G, Naresh DTV, Rajsekhar K. Prescription pattern of anticancer drugs in a tertiary care hospital. Journal of Evidence based Medicine and Healthcare, 2015; 2 (20): 3001-3009.

Mohandas K Mallath et al. The growing burden of cancer in India: epidemiology and social context. The Lancet Oncology, 2014; 15 (6): e205-e212.

Popoola AO, Omodele FO, Oludara MA, Ibrahim NA, Igwilo AI, Makanjuola SBL. Prevalence and pattern of cancers among adults attending a tertiary health institution in Lagos, Nigeria. IOSR Journal of Dental and Medical Sciences (IOSR-JDMS), 2013; 6 (3): 68-73.

Rathi AK, Saurabh Kumar, Abhishek Ashu, Singh K and Bahadur AK. Epidemiology of Pediatric Tumours at a Tertiary Care Centre. Indian Journal of Medical \& Paediatric Oncology, 2007; 28 (2): 33-35.

Sneha G, Aparna S, Sri Lakshmi BNVB, Sravya Varma A, Raju Naidu DS. Adjunctive drug utilization pattern in oncology department of a tertiary care hospital in south India. Indo American Journal of Pharma Research, 2015; 5 (3): 1297-1303.

Sunil K, Punam S, Madhuri K. Patterns of prescription and drug dispensing. Indian J Pediatr, 2005; 72: 117-121.

Takiar R, Nadavil D, Nandakumar A. Projections of number of cancer cases in India (2010-2020) by cancer groups. Asian Pac J Cancer Prev, 2010; 11 (4): 1045-9.

Yash N Goyal, Krunal C Solanki, Rusva A Mistry, Niasrg D Joshi, Anil P Singh, Maganlal V Gajera. Pattern of adverse drug reactions due to cancer chemotherapy in tertiary care teaching hospital in Gujarat. International Journal of Scientific Research, 2014; 3 (1): 333-335.

\section{How to cite this article:}

Mugada V, Paruchuri A, Munagala M. Drug Utilization Evaluation of Anticancer Drugs in a Tertiary Care Teaching Hospital: a Descriptive Observational Study. J App Pharm Sci, 2016; 6 (10): 098-101. 